\title{
Prevalence of Elevated Arterial Pressure and Associated Risk Factors in 10 to 15 Year Old Students from the Municipality of Cajazeiras-PB, Brazil

\section{Abstract}

Background: Overweight and obesity are rising in developing countries among all age groups. Children and adolescents are, therefore, exposed to higher risk of developing hypertension. Early identification can help avoiding or lessening complications through the life span. In order to plan adequate prevention programs, cities need to identify the prevalence of such condition. We aimed to identify the prevalence of Elevated Arterial Pressure (EAP) and associated factors in students from the municipality of Cajazeiras-PB, Brazil, a region in the Northeast of Brazil.

Methods and Findings: At this cross-sectional study, in 2011, we measured arterial pressure of 690 children and adolescents from both genders, age 10 to 15-year-old, following the parameters recommended by the Fourth Report on the Diagnosis, Evaluation and Treatment of High Blood Pressure in Children and Adolescents. We measured sociodemographic, behavioral, clinical, and hemodynamic variables. In the statistical analysis, we used the software Stata/IC 12.1. The significance level was established as $\mathrm{p} \leq .05$. In our total sample $55.4 \%$ were female, and the mean age was 12.8 years (SD: 1.4). Prevalence of EAP was $3.5 \%$ and it was associated with large waist circumference, overweight, experience of hunger, and tobacco exposure. The prevalence of systolic and diastolic hypertension were $2.5 \%$ and $1.7 \%$, respectively. In a logistic regression we observed that subjects exposed to tobacco were 2.65 times more likely to have EAP $(95 \% \mathrm{Cl}$ : 1.021 6.861), when compared to their not exposed peers. Those that ever experienced hunger had an odds ratio of 3.73 to present EAP $(95 \%$ Cl: 1.134-12.256).

Conclusions: The prevalence of EAP was within the average observed in previous studies at this age group. Routinely monitoring
Maria Lúcia O. Bezerra1, Fernanda C. Queirós ${ }^{2,3}$, Erlane A. F. de Freitas ${ }^{4}$, Rita Lucena ${ }^{3}$

1 Unidade Acadêmica de Enfermagem, Universidade Federal de Campina Grande, Campus de Cajazeiras Cajazeiras (PB), Brazil.

2 Laboratório de Eletroestimulação Funcional, Departamento de Biomorfologia, Instituto de Ciências da Saúde, Universidade Federal da Bahia Salvador (BA), Brazil.

3 Núcleo de Estudos em Neuromodulação, Departamento de Neurociências, Universidade Federal da Bahia - Salvador (BA), Brazil.

4 Unidade Acadêmica de Letras, Universidade Federal de Campina Grande, Campus de Cajazeiras Cajazeiras (PB), Brazil.

Contact information:

Maria Lúcia de Oliveira Bezerra.

Address: Avenida Mons. Abdon Pereira, No1001, Casas Populares. Cajazeiras PB, Brazil, 58900-000.

झ bezerramlo@hotmail.com 
of arterial pressure is important to early identification of EAP in this population. Stake holders in the state of Paraiba, Brazil, should include this monitoring in the protocol of pediatric visits in public health facilities.

\section{Keywords}

Students; High Blood Pressure;

Prevalence.

\section{Introduction}

Hypertension (HTN) is a syndrome mainly characterized by high systemic arterial blood pressure associated with cardiovascular, metabolic and hormonal changes [1]. Health of people worldwide is affected by HTN, which is considered one of the main modifiable associated factors of mortality by cardiovascular disease and stroke. Although HTN is more frequent in the elderly and adults [1], the prevalence of Elevated Arterial Pressure (EAP) in children and adolescents have been on the raise [2], ranging from $2.3 \%$ to nearly $8.0 \%$ in Brazil $[3,4]$. Research indicate that children with EAP are 2.4 times more likely to become adults with HTN [2]. Studies with students suggest that variability of arterial blood pressure levels depends of factors such as age, abdominal circumference and increased Body Mass Index (BMI) $[2,3,5]$.

In many cases, HTN is not associated with clinical symptoms, being considered a silent disease. Its detection is only possible through regular blood pressure monitoring. Measurement of arterial pressure in children and adolescents has been recommended at every clinical assessment after age three, at least annually as part of primary care, and must follow the standards established for adults. [1] Interpretation of Systolic Arterial Pressure and Diastolic Arterial Pressure readings in this population must take into account age, gender, and height according to the guideline of The Fourth Report on the Diagnosis, Evaluation, and Treatment of High Blood Pressure in Children and Adolescents. [4]

There are few studies in Brazil describing prevalence of EAP among children and adolescents in Brazil. Specifically, we did not identify any study on the municipality of Cajazeiras, in the estate of Paraíba (PB), Brazil, located in the Northeast of the country. Understanding the prevalence of EAP among students in this region is important to promote early detection and adequate intervention. Thus, this study aimed to determine EAP prevalence and associated risk factors among 10 to 15-year-old students from the municipality of Cajazeiras-PB, Brazil.

\section{Methods}

\section{Study design and sampling method}

We conducted a cross-sectional study with 10 to 15-year-old students from urban and rural areas of the Brazilian municipality Cajazeiras-PB, between September and October, 2011. We identified 33 target schools to be part of the sample using data from the city and state Secretaries of Education and Culture. Sample calculation was based on previous studies, considering the lowest prevalence rate of $1.2 \%$, and anticipating a 15\% sample loss. We used a multi-stage random sampling to select 11 schools and students in $6^{\text {th }}$ to $9^{\text {th }}$ grade. The final sample was proportional to the percentage of students enrolled in the study regions.

\section{Data collection}

General information. We used the Global-based Student Health Survey to assess adolescents' exposure to health-risk behaviors [6]. This survey has sections on demographics (e.g.: gender, age, re- 
sidential area), socioeconomic characteristics, and life characteristics (e.g.: exposure to tobacco and alcohol, dietary habits, practice of physical activities).

Anthropometric measurement. Height and weight were measured with a portable scale (Toledo). We followed the Centers for Diseases and Control and Prevention guidelines to collect data on waist circumference (WC) and BMI [7].

Arterial blood pressure. After five minutes of rest, Systolic Blood Pressure (SBP) and Diastolic Blood Pressure (DBP) were measured on the right arm, twice in a single visit, with a 2-minute interval; the lowest values were recorded. We classified as EAP measures for SBP and/or DBP equal or greater than the percentile 95 at reference tables for children and adolescents. Prevalence of EAP was estimated according to widely used criteria [8]. All measuring instruments were calibrated following the norms of the Brazilian National Institute of Metrology, Quality and Technology (Inmetro).

\section{Statistical analysis}

Data analysis were performed using Stata/IC 12.1 software. As data were not normally distributed, we used Mann-Whitney and Chi-Square/Fisher's exact tests to describe the data and investigating associations among EAP and study variables. To look at these associations, we used the criterion providing the highest prevalence (SBP or DBP elevated) to increase statistical power. We run a multiple logistic regression model using as independent variables those associated with EAP in the bivariate analysis. Statistical significant level was set to .05 .

\section{Ethical aspects}

This study was approved by the Institutional Review Board of the Health Sciences Center, Universidade Federal da Paraíba, Brazil (\#035/11).

\section{Results}

Among all participants, 55.4\% were females and $47 \%$ were self-classified, in terms of race/skin color, as "pardo"(brown). Average age was 12.8 years (SD: 1.38) and predominant monthly family income was one to four minimum wage (64.4\%). Around $77 \%$ lived in urban area and the majority of households (59.3\%) had four to six people. Mean values for WC and BMI were $70.9 \mathrm{~cm}$ (SD: 9.7) and 19.4 $\mathrm{kg} / \mathrm{m}^{2}$ (SD: 3.8). Average SBP was $101.0 \mathrm{mmHg}$ (SD: 12.4), while average DBP was $65.9 \mathrm{mmHg}$ (SD: 9.5). Table 1 presents sociodemographic, behavioral, and clinical characteristics of participants for the total sample, as well as bivariate association according to the presence of EAP.

EAP prevalence were as follows: 1) considering only increased DBP, 1.74\%; 2) considering only increased SBP, $2.46 \%$; 3) considering both increased DBP and SBP, .72\%; and 4) considering increased DBP or SBP, 3.48\%. Analysis used to identify factors associated with EAP considered its highest prevalence.

Comparison between individuals with and without EAP showed no association with gender, age, race/ skin color, residence area, religion, monthly family income, and number of people living in the household (Table 1). Among individuals with EAP, 16.7\% had experienced at least one episode of hunger in the past compared to $4.5 \%$ of those without EAP $(p=.026)$. EAP was also associated with exposure to tobacco $(p=.022)$, as well as high WC $(p=.001)$ and high BMI ( $p=.003)$ (Table 1). Students 13- to 15-year old presented higher SBP average compared to the 10- to 12-year old group. However, the difference was statistically significant only for males $(p<.05)$ (Table 2).

According to the bivariate analysis, episodes of hunger in the past, exposure to tobacco, waist circumference, and BMI were associated with EAP. Thus, we modeled a multinomial logistic regression using these four variables as predictors of EAP. We found statistically significant association among ex- 
Table 2. Comparison among mean systolic blood pressure, diastolic blood pressure according to age categories and gender for 690 students, 10-to-15-year-old, of Cajazeiras-PB, Brazil.

\begin{tabular}{|c|c|c|c|c|c|c|}
\hline \multirow{2}{*}{ Gender } & \multirow{2}{*}{$\begin{array}{c}\text { Arterial Pressure Type } \\
(\mathrm{mmHg})\end{array}$} & \multicolumn{2}{|c|}{10 to 12 years } & \multicolumn{2}{|c|}{13 to 15 years } & \multirow{2}{*}{$P$-value } \\
\hline & & $N$ & Mean (SD) & N & Mean (SD) & \\
\hline \multirow{2}{*}{ Female } & SBP & 179 & 99.58 (11.77) & 203 & $101.38(11.80)$ & .115 \\
\hline & DBP & 179 & 65.92 (9.75) & 203 & $65.76(8.90)$ & .890 \\
\hline \multirow[t]{2}{*}{ Male } & SBP & 127 & $98.29(11.41)$ & 181 & $103.87(13.63)$ & $.001^{*}$ \\
\hline & DBP & 127 & $63.78(8.90)$ & 181 & $67.43(10.09)$ & $.002^{*}$ \\
\hline
\end{tabular}

Table 3. Odds ratio for elevated arterial pressure among 690 students, 10-to-15-year-old, of Cajazeiras-PB, Brazil.

\begin{tabular}{|c|c|}
\hline \multirow{2}{*}{ Variables } & Elevated Arterial Pressure ${ }^{a}$ \\
\hline & OR $(95 \% \mathrm{Cl})$ \\
\hline WC $(\mathrm{cm})$ & $1.01(.953-1.075)$ \\
\hline $\mathrm{BMI}\left(\mathrm{kg} / \mathrm{m}^{2}\right)$ & $1.13(.977-1.303)$ \\
\hline $\begin{array}{l}\text { Ever experienced } \\
\text { hunger }\end{array}$ & $3.73 *(1.134-12.256)$ \\
\hline $\begin{array}{l}\text { Exposure to tobacco } \\
\text { (active or passive } \\
\text { smoking) }\end{array}$ & $2.65 *(1.021-6.861)$ \\
\hline \multicolumn{2}{|c|}{$\begin{array}{r}\text { Table presents results of logistic regression comparing students } \\
\text { with and without elevated arterial pressure (reference categories: } \\
\text { never experienced hunger, not exposed to tobacco). }\end{array}$} \\
\hline \multicolumn{2}{|c|}{$\begin{array}{l}\text { a The referent group is the group without Elevated Arterial } \\
\text { Pressure. }\end{array}$} \\
\hline & * Statistically significant. \\
\hline $\begin{array}{l}\text { WC }=\text { Waist } C \\
\text { OR }\end{array}$ & $\begin{array}{l}\text { nference; BMI = Body Mass Index; } \\
\text { ds Ratio; Cl = Confidence Interval. }\end{array}$ \\
\hline
\end{tabular}

posure to tobacco, episodes of hunger in the past and EAP (Table 3). Students exposed to tobacco were 2.65 times more likely to present EAP when compared to those not exposed (95\% Cl:1.0216.861). On the other hand, those that reported episodes of hunger in the past were 3.73 more likely to present EAP compared to peers not exposed to hunger (95\% Cl: 1.134-12.256).

\section{Discussion}

Prevalence of EAP in this study was 3.5\%, which is within a range of 1.2 to $13 \%$ observed in previous similar studies. In bivariate analysis, we observed that EAP was associated with exposure to tobacco, experience of hunger in the past, high WC and BMI. In out multivariate model, students exposed to tobacco or who ever experienced hunger were more likely to present EAP.

A study in the United States found a prevalence of $2.7 \%$ for elevated systolic blood pressure and $2 \%$ for elevated diastolic blood pressure among 10- to 15-year old students [3]. In South Africa, the variation was from $2.3 \%$ to $5.9 \%$ [9]. In Brazil, prevalence rates varied between $2.3 \%$ [4] and $7.7 \%$ [10]. Several factors influence the variability in these prevalence, such as time when blood pressure was measured and number of subjects from different age groups [11].

Participants with EAP reported more episodes of hunger in the past. Although our confidence interval is wide (95\% IC: 1.134-12.256) and our results need to be interpreted with cautious, it has been suggested that hypertension is more frequent among the poorest [12] and experience of hunger is a proxy for lower socioeconomic status. Average values for SBP and DBP were higher for 13- to 15-year old males compared to their younger peers (Table 3). This difference is statistically significant and clinically relevant given that essential hypertension tends to be more frequent among adolescents and young adults [13].

We found a significant association between exposure to tobacco and EAP in exploratory multivariate analysis. A link between EAP and tobacco exposure has been described before $[10,14]$. Tobacco use is considered the lead cause of mortality 
in cardiovascular diseases. Quitting the habit does not reduce pressoric levels, but reduces cardiovascular risks [1]. The habit of smoking tobacco usually starts during childhood. A study conducted in the south region of Brazil reported a prevalence of $12.1 \%$ of tobacco use among children and adolescents between ages 10 and 19 [15]. In the same study, the authors found that $75 \%$ of subjects with elevated arterial blood pressure were exposed to tobacco.

We also observed, in bivariate analysis, an association between EAP and BMI, as described by other authors [16]. Although the significance did not hold in the multivariate analysis, relationship between EAP and obesity has been reported in epidemiologic studies with children and adolescents [16, 17]. Larger WC has been associated with reduced HDL cholesterol, as well as increased triglycerides, EAP, and left ventricular volume, as observed in adults [18]. Implication of this finding is worrisome because obese children and adolescents are at higher risk to present HNT in adulthood and more likely to develop cardiovascular disease [4].

As any other studies, ours had strengths and limitations. We used a prospective design and the computed sample size was inflated, which allowed to collect information for the estimated sample size. This approach reduces information bias in our results. Moreover, in combination with the stratification of the sample proportionally to the percentage of students enrolled in the study regions, this sample can be considered representative of students between ages 10 and 15 enrolled in the school system of the municipality of Cajazeiras-PB, Brazil in the academic year of 2011. An important limitation of our study is the inability of making inferences of causality because of its cross-sectional design; the associations presented are only exploratory. Some categories in the multivariate analysis had small cell sizes (between four and six observations). Therefore, results should be interpreted cautiously. Data presented here, however, can be used to support designing specific programs to monitor arterial pressure in children and adolescents, as well as to inform future studies in this municipality.

\section{Conclusion}

To sum up, this study found that prevalence of EAP among students from the municipality of CajazeirasPB is within the average observed among Brazilian students. EAP was especially associated with exposure to tobacco and episodes of hunger in the past. Current findings add to a growing body of literature on the importance of assessing arterial blood pressure in students because high values are predictors of HNT and associated complications through the life span.

\section{Authors' contribution}

MLOB conceived and designed the study; she collected and interpreted data and drafted the manuscript. FCQ analyzed and interpreted data; she revised the manuscript for important intellectual content. EAFF helped with data collection and interpretation; she also drafted the manuscript. RL conceived and designed the study; she helped with data interpretation and revised the manuscript for important intellectual content. All authors approved the final version of the manuscript.

\section{Funding}

Maria Lúcia de Oliveira Bezerra received a CAPES/ DINTER Doctoral Award for Medicine and Health/ UFCG-UFBA, Process \# 2358/2009. (Cajazeiras-PB, Brazil). Fernanda C. Queirós is a CAPES post-doctoral fellow, with an award from the project Visiting Scholar, number 2947/2013.

\section{Conflicts of interest}

The authors declare no conflict of interest. 


\section{References}

1. Sociedade Brasileira de Cardiologia, Sociedade Brasileira de Hipertensão, Sociedade Brasileira de Nefrologia. VI Diretrizes Brasileiras de Hipertensão. Arq Bras Cardiol 2010; 95(1 Supl. 1): 1-51.

2. Garcia F, Terra A, Queiroz A, Correia C, Ramos P, Ferreira Q, et al. Evaluation of risk factors associated with increased blood pressure in children. J Pediatr 2004; 80(1): 29-34.

3. Adrogué $H$, Sinaiko A. Prevalence of hypertension in junior high school-aged children: Effect of new recommendations in the 1996 Updated Task Force Report. Am J Hypertens 2001; 14(5 i): 412-414.

4. Borges L, Peres M, Horta B. Prevalência de níveis pressóricos elevados em escolares de Cuiabá, Mato Grosso Prevalence of high blood pressure among schoolchildren in Cuiabá, Midwestern Brazil. Rev Saude Publica 2007; 41(4): 530-538.

5. Mohan B, Kumar N, Aslam N, Rangbulla A. Prevalence of sustained hypertension and obesity in urban and rural school going children in Ludhiana. Indian Heart J 2004; 56(4): 310-314.

6. World Health Organization. Global school-based student health survey (GSHS). 2011; Available at: http://www.who.int/chp/ gshs/en/. Accessed June/16, 2011.

7. Centers for Disease Control and Prevention (CDC). Body Mass Index. 2011; Available at: http://www.cdc.gov/healthyweight/ assessing/bmil. Accessed June/10, 2011

8. National High Blood Pressure Education Program Working Group on High Blood Pressure in Children and Adolescents. The fourth report on the diagnosis, evaluation, and treatment of high blood pressure in children and adolescents. Pediatrics 2004; 114(2 Suppl $4^{\text {th }}$ Report): 555-576.

9. Moselakgomo V, Toriola A, Shaw B, Goon D, Akinyemi O. Body mass index, overweight, and blood pressure among adolescent schoolchildren in Limpopo province, South Africa. Rev Paul Pediatr 2012; 30(4): 562-569.

10. Silva MA, Rivera IR, Ferraz MR, Pinheiro AJ, Alves SW, Moura $A A$, et al. Prevalence of cardiovascular risk factors in child and adolescent students in the city of Maceio. Arq Bras Cardiol 2005; 84(5): 387-392.

11. Christofaro DGD, Andrade SM, Fernandes RA, Cabrera MAS, RittiDias RM. Prevalência de pressão arterial elevada em crianças e adolescentes: revisão sistemática. Rev Bras Saude Mater Infant 2011; 11(4): 361-367.

12. Rouquayrol M, Veras F, Vasconcelos J, Bezerra R, Gomes I, Bezerra F. Fatores de risco na doença coronariana: inquérito epidemiológico em estratos habitacionais de um bairro de Fortaleza. Arq Bras Cardiol 1987; 49(6): 339-347.

13. Silva $D$, Matos $A$, Magalhães $T$, Martins V. Prevalência de hipertensão arterial em adolescentes portugueses da cidade de Lisboa. Rev Port Cardiol 2012; 31(12): 789-794.
14. Araújo TL, Lopes MVO, Oliveira ARS, Chaves DBR, Costa AGS, Alves FEC, et al. Fatores de risco para hipertensão arterial em escolares: um estudo de caso-controle. Rev enferm UERJ 2008; 16(2): 149-155.

15. Malcon MC, Menezes AMB, Chatkin M. Prevalência e fatores de risco para tabagismo em adolescentes. Revista de Saúde Pública 2003; 37(1): 1-7.

16. Diniz J, Silva J, Silva A, Junior $M$, Heringer $S$, Batista $P$, et al. Hipertensão arterial: estudo retrospectivo em crianças referendadas a uma unidade de nefrologia pediátrica. J Pediatr 1994; 70(4): 226-233.

17. Moser D, Giuliano Ide C, Titski A, Gaya A, Coelho-e-Silva M, Leite N. Anthropometric measures and blood pressure in school children. J Pediatr 2013; 89(3): 243-249.

18. Gubert MB, Portela RS. Estado nutricional e hipertensão arterial entre adolescentes em Brasília. Revista Digital Buenos Aires 2010; 146: 05.

\section{Comment on this article:}

\section{A $[3$ in $8+\mathbf{S} P$}

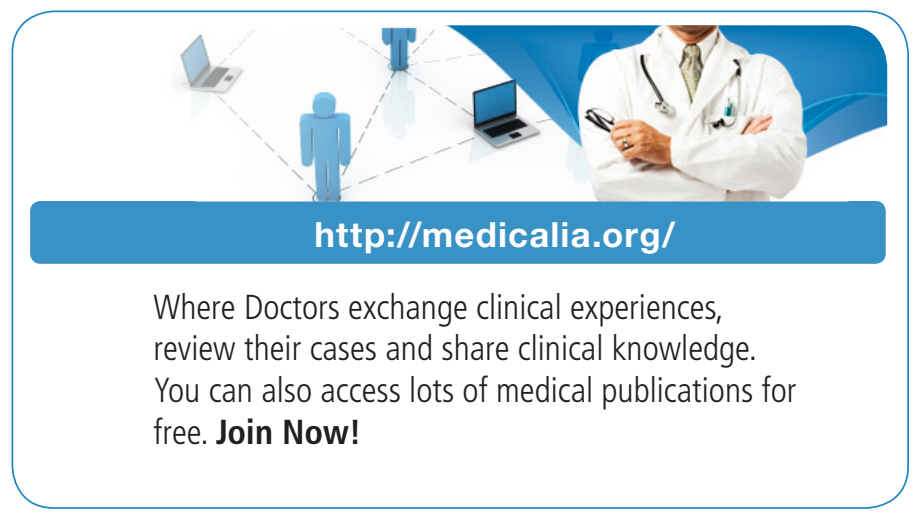

Publish with iMedPub

http://www.imed.pub

International Archives of Medicine is an open access journal publishing articles encompassing all aspects of medical science and clinical practice. IAM is considered a megajournal with independent sections on all areas of medicine. IAM is a really international journal with authors and board members from all around the world. The journal is widely indexed and classified Q1 in category Medicine. 